\title{
FINANCIAMENTO DE PARTIDOS POĹ́TICOS NAS ELEIÇÕES DE 2008 E 2012: ANÁLISE DAS EMPRESAS DOADORAS
}

\author{
FINANCING POLITICAL PARTIES IN THE 2008 AND 2012 ELECTIONS: AN ANALYSIS OF DONOR COMPANIES \\ LA FINANCIACIÓN DE LOS PARTIDOS POLÍTICOS EN LAS ELECCIONES DE 2008 Y 2012: ANÁLISIS DE LAS EMPRESAS \\ DONANTES
}

Resumo: A motivação deste trabalho foi a observação do processo eleitoral sob o ponto de vista do usuário externo das informaç̧ões contábeis. Para tanto, buscou-se investigar como se dá a divulgação de dados sobre o processo eleitoral pelas empresas listadas na BM\&FBovespa, que fizeram doações a partidos políticos nas eleições municipais de 2008 e 2012. Por meio do sistema de Divulgação Externa, foram obtidas as Informações Anuais e os Demonstrativos Financeiros Padronizados de 11 empresas selecionadas, analisando-se os dados referentes ao controle sobre outras entidades, além da DR, DFC, Nota Explicativa e Relatório da Administração das empresas em busca de referência a doações efetuadas a partidos políticos. Concluiu-se que apenas uma das 11 empresas selecionadas evidenciou a realização de doações a partidos políticos por meio dos demonstrativos e apenas no ano de 2008, não sendo possível identificar os valores doados nem os critérios adotados para escolha dos partidos contemplados.

Palavras-chave: evidenciação; partidos políticos; informação contábil; eleições; transparência.

Jardson Edson Guedes da Silva Almeida - jardson_guedes@yahoo.com.br

Professor do Centro Universitário Tiradentes, Assistente I, Maceió, AL, Brasil.

Luiz Antônio Félix Júnior - juniorfelixx@hotmail.com

Faculdade Internacional da Paraíba, Escola de Negócios, João Pessoa, PB, Brasil.

Umbelina Cravo Teixeira Lagioia - umbelinalagioia@gmail.com

Universidade Federal de Pernambuco, Doutora no Programa de Pós-Graduação em Ciências Contábeis, Recife, PE, Brasil.

Juliana Araújo - juhliana.araujo@gmail.com

Doutoranda em Administração pela Universidade Federal de Pernambuco, Recife, PE, Brasil.

João Gabriel Nascimento Araújo - j_gabriel90@hotmail.com

Doutorando em Ciências Contábeis pela Universidade Federal de Pernambuco, Recife, PE, Brasil.

Artigo submetido no dia 15-04-2015 e aprovado em 19-01-2016.

DOl: http://dx.doi.org/10.12660/cgpc.v21n68.48758 


\section{Abstract}

The motivation of this study was to observe the electoral process from the point of view of the external user of accounting information. Therefore, we sought to investigate how information about the electoral process is disclosed by the companies involved in companies listed on the BM \& FBOVESPA and that made donations to political parties in the municipal elections of 2008 and 2012. Annual Information and the Standardized Financial Statements of eleven selected companies were obtained from the External Disclosure system and an analysis was made of the data for controlling companies, in addition to the DR, DFC, Explanatory Note and Management Report of the companies, in a search for reference to donations made to political parties. The conclusion was that only one of the eleven companies selected produced evidence of making donations to political parties by way of their statements and only in 2008; it was impossible to identify what amounts were donated or the criteria used in selecting the parties that benefited.

Keywords: disclosure; political parties; accounting information; elections; transparency.

\section{Resumen}

La motivación de este estudio fue la observación del proceso electoral desde el punto de vista del usuario externo de la información contable. Por lo tanto, tratamos de investigar cómo se obtuvo la difusión de información sobre el proceso electoral por las empresas que participan en empresas que cotizan en el mercado BM\&FBOVESPA que hicieron donaciones a los partidos políticos en las elecciones municipales de 2008 y 2012. A través del Sistema de difusión externa de la Información Anual y los Estados Financieros Estandarizados de once empresas seleccionadas, analizamos los datos para el control de las empresas distintas de la DR, DFC, Note y el informe de gestión de las empresas que buscan referencia a las donaciones a los partidos políticos. Se concluyó que sólo una de las once empresas seleccionadas destacó la realización de donaciones a los partidos políticos a través de los estados contables y sólo en 2008, no siendo posible identificar que donó los valores o los criterios utilizados para seleccionar las partes cubiertas.

Palabras clave: divulgación; partidos politicas; información contable; elecciones; transparencia.

\section{INTRODUÇÃO}

A receita dos partidos políticos tem sua origem em doações e contribuições de recursos financeiros de pessoas físicas e jurídicas, além das cotas do Fundo Especial de Assistência aos Partidos Políticos (Fundo Partidário), constituído por multas e penalidades eleitorais, recursos financeiros legais, doações espontâneas privadas e dotações orçamentárias públicas. De acordo com os artigos 32 e 33 da Lei dos partidos políticos, em suas prestações de contas à Justiça Eleitoral, os partidos devem apresentar a discriminação e a destinação dos valores recebidos do Fundo Partidário, além do valor e da origem das contribuições e doações recebidas.

A divulgação das pessoas físicas e jurídicas que realizaram essas doações é um grande instrumento de controle social do processo eleitoral, trazendo a possibilidade de acompanhamento pela população da movimentação financeira dos partidos políticos. Porém, esse é apenas um lado da questão, visto que por si só a divulgação das empresas que contribuíram para as campanhas não é suficiente para garantir a transparência do processo eleitoral. Para isso é preciso observar essa questão sob outro ponto de vista e analisar as informações das empresas que participam do processo eleitoral como doadoras de recursos a candidatos ou a partidos políticos. Nem todas as empresas sofrem a imposição legal de divulgação de informações ao público, entretanto as companhias de capital aberto que negociam suas ações na BM\&FBovespa devem cumprir algumas exigências no que diz respeito à divulgação de informações econômico-financeiras e administrativas sobre a entidade. Essas infor- 
mações ficam disponíveis na internet para acesso tanto pelos acionistas como pela população em geral interessada.

Schultz, Marques e Hofer (2010) comentam que os maiores níveis de evidenciação compulsória são registrados junto às companhias de capital aberto, com o objetivo de proteger interesses dos usuários externos (acionistas, associados, fornecedores, credores, bancos, governo, sociedade etc.) e dar estabilidade e transparência ao mercado de capitais como um todo. Nas demais empresas, existem diferentes níveis de evidenciação compulsória, geralmente bem mais modestos e, até mesmo, a desobrigação da publicação de informações a respeito da entidade.

Pereira (2008) comenta que a teoria contábil contemporânea se preocupa com as questões sobre a quantidade e a qualidade das informações fornecidas aos usuários externos à entidade empresarial. A motivação deste trabalho surge a partir desse ponto, com o propósito de observar o processo eleitoral sob o ponto de vista do usuário externo das informações contábeis e investigar de que maneira se dá a divulgação de informações relativas ao processo eleitoral por parte das empresas nele envolvido.

Por esse motivo, o estudo objetivou analisar se as empresas listadas na BM\&FBovespa que fizeram doações a partidos políticos nas eleições de 2008 e 2012 evidenciaram esse fato em seus demonstrativos financeiros.

\section{REFERENCIAL TEÓRICO}

2.1 Segmentos especiais de listagem na BM\&FBovespa
A abordagem de Governança Corporativa no Brasil está intimamente ligada ao mercado de capitais. Lagioia (2007, p. 107) define Governança Corporativa como "conjunto de regras, normas, e práticas de conduta definidas pela BM\&FBovespa e destinadas a oferecer maior transparência aos investidores e melhor preço/custo de captação para as empresas." A BM\&FBovespa (2005) define que as práticas diferenciadas de governança corporativa formam "um conjunto de normas de conduta para empresas, administradores e controladores, considerados importantes para a valorização das ações e outros ativos emitidos pelas companhias".

Em 2000, foram criados os segmentos de governança corporativa para determinar às empresas já listadas na BM\&FBovespa uma série de práticas e comportamentos relevantes a serem contemplados por seus gestores. Diante do elevado rigor e da expectativa do não atendimento por muitas empresas quanto ao segmento Novo Mercado, a BM\&FBovespa decidiu pela criação de dois novos níveis de governança corporativa: o nível 1 e o nível 2, os quais distinguem as empresas de acordo com 0 grau de compromisso assumido com a prática de boa governança. O Novo Mercado foi criado para constituir-se no segmento da BM\&FBovespa, destinado às empresas que se comprometem com práticas e regras societárias mais rígidas do que as exigidas pela legislação brasileira. Aderindo ao Novo Mercado, as organizações deveriam expandir os direitos dos acionistas e divulgar suas informações de maneira ordenada e mais transparente aos usuários, otimizando a liquidez e a valorização das ações. 
As empresas contempladas no nível 1 se comprometem, principalmente, com a realização de melhorias na prestação de informações ao mercado e com a dispersão acionária. O principal ponto a ser observado por elas se refere à qualidade e à quantidade das informações de suas responsabilidades quanto às Demonstrações Contábeis Trimestrais, às Demonstrações Financeiras Padronizadas e aos Informes Anuais. Tais relatórios já eram obrigatórios às empresas antes do surgimento dos níveis diferenciados de governança, assim, a mudança está na profundidade da evidência de tais informações. Isso pode explicar o porquê de algumas empresas terem aderido ao Nível 1 no primeiro mês de existência, junho de 2001.

Outra vertente a ser analisada nas normas iniciais, em relação ao primeiro estágio de transição para o Novo Mercado, refere-se ao percentual de ações emitidas que deveria permanecer em circulação, que era de, no mínimo, 25\%. Tal percentual nem sempre era possível de ser atendido de imediato, o que provocou a reformulação do critério e o percentual passou a ser contemplado como meta a ser atingida em um prazo negociado entre a BM\&FBovespa e a própria empresa. No nível 2, além da aceitação das obrigações contidas no nível 1, a empresa e seus gestores devem utilizar um conjunto bem mais amplo de práticas de governança e de direitos adicionais para os acionistas minoritários, uma vez que, além de cumprirem as exigências do Nível I, precisam divulgar suas informações contábeis anuais segundo os padrões estabelecidos pelo International Accounting Standards Board (IASB) ou pelo Financial Accounting Standards Board (FASB). Ademais, há a exigência de ex- tensão das mesmas condições obtidas pelos gestores quando da venda da companhia para todos os acionistas detentores de ações ordinárias e de, no mínimo, $70 \%$ desse valor para os detentores de ações preferenciais.

A criação do Novo Mercado marcou uma nova fase do mercado de capitais no Brasil, onde o setor privado assumiu a liderança na condução das reformas. Essa iniciativa foi bem recebida por investidores, empresas, órgãos reguladores e governo e marcou também uma mudança de postura da BM\&FBovespa, que, como o contrato de adesão é administrado por ela, passa a ser a guardiã das práticas de governança corporativa. Isso sugere a adoção da prática da autorregulação e que a promoção do mercado de capitais pode ser feita sem as amarras do Estado. Deve-se notar que o Novo Mercado não requer um sistema operacional diferenciado do mercado tradicional. Ele funciona como um selo de qualidade, cujo valor reside nas obrigações contratuais assumidas pela empresa e de acordo como a BM\&FBovespa administra tais contratos. As companhias que aderirem ao Novo Mercado devem seguir regulamentações mais rígidas que as do Nível 2 , porém, tendo como principal diferença o fato de ficarem restritas à emissão de ações ordinárias.

Inserida nesse contexto e para resolver os conflitos que surgirem entre acionistas e companhias que aderirem ao Nível 2 ou ao Novo Mercado, a BM\&FBovespa criou a Câmara de Arbitragem, objetivando determinar a solução adequada de cada caso com tempestividade, propiciando melhor eficiência na resolução de controvérsias, já que os processos tendem a ser concluídos mais rapidamente, pois são tratados na esfera pri- 
vada, por intermédio de árbitros. A seguir, apresenta-se de forma simplificada uma comparação entre os segmentos especiais de listagem na BM\&FBovespa.

Tabela 1. Segmentos especiais de listagem na BM\&FBovespa

\begin{tabular}{|l|l|l|l|}
\hline & Nível 1 & Nível 2 & Novo Mercado \\
\hline $\begin{array}{l}\text { Característica es- } \\
\text { sencial }\end{array}$ & Transparência. & $\begin{array}{l}\text { Transparência e mais poder } \\
\text { aos minoritários }\end{array}$ & $\begin{array}{l}\text { Transparência e poder igual para todos os } \\
\text { acionistas }\end{array}$ \\
\hline $\begin{array}{l}\text { Características das } \\
\text { ações emitidas }\end{array}$ & $\begin{array}{l}\text { Permite a exis- } \\
\text { tência de ações } \\
\text { ordinárias e ações } \\
\text { preferenciais }\end{array}$ & $\begin{array}{l}\text { Permite a existência de } \\
\text { ações ordinárias e ações } \\
\text { preferenciais com direitos } \\
\text { adicionais }\end{array}$ & $\begin{array}{l}\text { Permite apenas a existência de ações ordi- } \\
\text { nárias }\end{array}$ \\
\hline $\begin{array}{l}\text { Conselho de admi- } \\
\text { nistração }\end{array}$ & $\begin{array}{l}\text { Mínimo de três } \\
\text { membros confor- } \\
\text { me legislação }\end{array}$ & Mínimo de cinco membros, sendo pelo menos um independente \\
\hline $\begin{array}{l}\text { Demonstrações } \\
\text { financeiras anuais } \\
\text { em Padrão Interna- } \\
\text { cional }\end{array}$ & Facultativo & US GAAP ou IFRS \\
\hline $\begin{array}{l}\text { Adoção da câmara } \\
\text { de arbitragem do } \\
\text { mercado }\end{array}$ & Facultativo & Obrigatório \\
\hline $\begin{array}{l}\text { Percentual mínimo } \\
\text { de ações em circu- } \\
\text { lação }\end{array}$ & No mínimo 25\% de free float \\
\hline
\end{tabular}

Fonte: Elaboração do autor com base nas informações da BM\&FBovespa

A entrada em um desses segmentos significa para a empresa ingressante, a conquista de uma melhora de imagem para com a sociedade e com o mercado, uma vez que passa a ser de conhecimento público a aderência de um exigente conjunto de regras societárias, conhecidas como "práticas diferenciadas de governança corporativa". Inicialmente, a definição de governança corporativa era utilizada pelo prisma da transparência das práticas contábeis de empresa de capital aberto. Atualmente, é vista como aspecto basilar para o sucesso das organizações.

\subsection{Relatório da administração}

Para Hendriksen e Van Breda (1999), a divul- gação de informações financeiras tradicionalmente visa dar suporte à tomada de decisões dos investidores sobre a melhor forma de alocação de seus recursos. Entre as várias formas de divulgação de informações, ludícibus (2010) relaciona as seguintes: a) forma e apresentação das demonstrações contábeis; b) informações entre parênteses; c) notas explicativas; d) quadro e demonstrativos suplementares; e) comentários do auditor; f) relatório da administração.

Conforme explicam ludícibus, Martins e Gelbcke (2010), no Brasil, existe um conjunto de documentos apreciados pela Assembleia Geral que representam a "prestação de contas" das sociedades anônimas por ações. E 
entre eles está o Relatório da Administração. Esse conjunto de documentos é de publicação obrigatória segundo o art. 133 da Lei n. 6.404, de 15 de dezembro de 1976, alterado pela Lei n. 10.303/01.

Yuthas, Rogers e Dillard (2002) consideram que o texto contido nos relatórios da administração é amplamente lido por uma variedade de stakeholders e analistas. Distorções significativas feitas pelos gestores podem trazer malefícios a longo prazo se for descoberto que essas distorções informacionais teriam afetado a percepção dos demonstrativos financeiros.

A prática de realizar relatos sobre operações da companhia é realizada desde a década de 1960 nos Estados Unidos, por meio do ínterim e do segment reporting. O relatório de administração surgiu com várias empresas que, por atuarem em diferentes segmentos econômicos, passaram a evidenciar voluntariamente essas informações com as demonstrações financeiras anuais.

Em 1970, esse relatório foi regulamentado pela SEC e passou a integrar os relatórios financeiros anuais das companhias. Apesar dos benefícios, como a apresentação de "dados escondidos" pelas demonstrações financeiras, Delaney et al. (1996) apresentam alguns argumentos usados nos Estados Unidos contra a publicação das operações da empresa, como a evidenciação de informações aos concorrentes, sindicatos e governo, que podem trazer danos à empresa, e essa divulgação desencoraja a administração a tomar decisões com risco razoável em virtude da obrigação de repor- tar resultados desfavoráveis.

No Brasil, o art. 133 da Lei n. 6.404, de 15 de dezembro de 1976, alterado pela Lei $n$. $10.303 / 01$, determina também que os administradores divulguem até um mês antes da assembleia geral ordinária o Relatório da Administração contendo informações sobre "os negócios sociais e os principais fatos administrativos do exercício findo". No entanto, uma regulamentação mais clara sobre o conteúdo do RAd só ocorreu em 1987 com o Parecer de Orientação n. 15/87 da Comissão de Valores Mobiliários (CVM). Em 3 de outubro de 2005, a CVM, por meio da Deliberação n. 488, aprovou o Pronunciamento Ibracon NPC n. 27, que comenta sobre o conteúdo mínimo dos relatórios.

Outro ponto que deve ser observado na confecção dos relatórios diz respeito ao conteúdo, não sendo válida a simples apresentação de percentuais que podem ser obtidos por qualquer leitor das demonstrações contábeis, visto que a informação relevante diz respeito ao comentário ou apreciação dos fatores endógenos e exógenos que influenciaram as variações incorridas.

O relatório da administração, como peça integrante das demonstrações financeiras, deverá complementar as peças contábeis e as notas explicativas, observada a devida coerência com a situação nelas espelhada, formando um quadro completo das posturas e do desempenho da administração na gestão e alocação dos recursos que estão a elas confiados. A seguir, apresenta-se uma tabela que contempla tais informações. 
FINANCIAMENTO DE PARTIDOS POLÍTICOS NAS ELEIÇÕES DE 2008 E 2012: ANÁLISE DAS EMPRESAS DOADORAS

Tabela 2. Informações obrigatórias contidas no relatório da administração

\begin{tabular}{|c|c|c|}
\hline Elemento & \multicolumn{2}{|c|}{ Descrições } \\
\hline $\begin{array}{l}\text { Descrição dos negócios, produtos e servi- } \\
\text { ços }\end{array}$ & $\begin{array}{l}> \\
> \\
> \\
>\end{array}$ & $\begin{array}{l}\text { Ramo da atividade da companhia } \\
\text { Principais produtos } \\
\text { Áreas de atuação } \\
\text { Dados físicos sobre vendas } \\
\text { Informações sobre o segmento de atuação }\end{array}$ \\
\hline $\begin{array}{l}\text { Comentários sobre a conjuntura econômica } \\
\text { geral }\end{array}$ & $\begin{array}{l}> \\
>\end{array}$ & $\begin{array}{l}\text { Variáveis econômicas } \\
\text { Variáveis legais e fiscais } \\
\text { Variáveis governamentais } \\
\text { Variáveis políticas } \\
\text { Variáveis ambientais } \\
\text { Variáveis sociais } \\
\text { Outros fatores exógenos }\end{array}$ \\
\hline Recursos Humanos & $>$ & $\begin{array}{l}\text { Quantidade de empregados } \\
\text { Divisão geográfica da mão de obra } \\
\text { Nível educacional } \\
\text { Investimentos em treinamento }\end{array}$ \\
\hline Investimentos & $>$ & $\begin{array}{l}\text { Inversões de recursos em imobilizado } \\
\text { Aplicações no diferido } \\
\text { Outras inversões para futura imobilização }\end{array}$ \\
\hline Pesquisa e desenvolvimento & $>$ & Atual estágio dos projetos, recursos alocados e montantes aplicados \\
\hline Novos produtos e serviços & & $\begin{array}{l}\text { Novos produtos e serviços colocados no mercado } \\
\text { Expectativas relativas a esses produtos e serviços }\end{array}$ \\
\hline Proteção ao meio ambiente & & $\begin{array}{l}\text { Inversões em projetos de proteção ecológica } \\
\text { Objetivos das inversões e valores envolvidos }\end{array}$ \\
\hline Reformulação administrativa ou societária & $>$ & $\begin{array}{l}\text { Mudanças efetuadas } \\
\text { Reorganizações societárias } \\
\text { Programas de racionalização }\end{array}$ \\
\hline Investimentos em controladas e coligadas & $>$ & $\begin{array}{l}\text { Objetivos pretendidos com as inversões ou alienações realizadas nas controladas } \\
\text { ou coligadas }\end{array}$ \\
\hline Direitos dos acionistas e dados do mercado & $>$ & $\begin{array}{l}\text { Políticas relativas à distribuição de dividendos } \\
\text { Desdobramentos e grupamentos de ações } \\
\text { Valor patrimonial por ação } \\
\text { Volume negociado no período } \\
\text { Cotação das ações em bolsa de valores }\end{array}$ \\
\hline $\begin{array}{l}\text { Perspectivas e planos para o exercício em } \\
\text { curso e futuros }\end{array}$ & $>$ & $\begin{array}{l}\text { Expectativas quanto aos exercícios correntes e futuros com base em premissas e } \\
\text { fundamentos explicitamente colocados }\end{array}$ \\
\hline Empresas investidoras & $>$ & Informações anteriormente recomendadas relativas a empresas investidas \\
\hline
\end{tabular}

Fonte: Adaptado de ludicibus, Martins e Gelbcke apud Pereira (2008, p. 33) 
Jardson Edson Guedes da Silva Almeida, Luiz Antônio Félix Júnior, Umbelina Cravo Teixeira Lagioia, Juliana Araújo, João Gabriel Nascimento Araújo

Para Hendriksen e Van Breda (1999) é muito forte a tendência de que as companhias divulgarão toda a informação necessária para o bom funcionamento do mercado. Embora não exista um consenso sobre quais seriam as informações de natureza voluntária em relatórios anuais das companhias. A seguir, apresenta-se um quadro contemplando tais informações.

Tabela 3. Informações voluntárias contidas no relatório da administração

\begin{tabular}{|c|c|}
\hline Elemento & Descrições \\
\hline $\begin{array}{l}\text { Informações gerais e não financei- } \\
\text { ras }\end{array}$ & $\begin{array}{l}>\text { Principais mercados e market share } \\
>\text { Estratégia (metas e objetivos) } \\
>\text { Ambiente de negócios e fatores críticos de acesso } \\
>\text { Eventos importantes no ano } \\
>\text { Estrutura organizacional } \\
>\text { Relatório social ou demonstração do valor adicionado } \\
>\text { Eficiência operacional }\end{array}$ \\
\hline $\begin{array}{l}\text { Informações financeiras adiciona- } \\
\text { das }\end{array}$ & $\begin{array}{l}>\text { Unidades vendidas } \\
>\text { Retorno sobre o patrimônio } \\
>\text { Retorno sobre o ativo } \\
>\text { Ebitda } \\
>\text { Demonstração do fluxo de caixa }\end{array}$ \\
\hline $\begin{array}{l}\text { Análise de tendências e discussão e } \\
\text { análise gerencial }\end{array}$ & $\begin{array}{l}>\text { Tendência da receita ao longo dos últimos anos } \\
>\text { Vendas por região e/ou unidade de negócio } \\
>\text { Tendência do lucro operacional ao longo dos últimos anos } \\
>\text { Investimento por região e/ou unidade de negócio } \\
>\text { Tendência de comportamento das ações e retorno total para o acionista } \\
>\text { Discussão sobre mudanças no lucro operacional }\end{array}$ \\
\hline 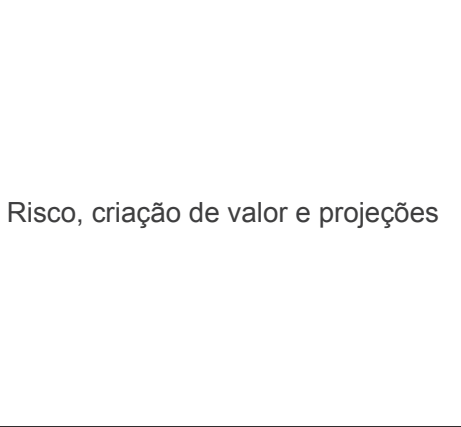 & $\begin{array}{l}>\text { Uso e implementação de gestão de risco } \\
>\text { Exposição ao risco cambial } \\
>\text { Medidas quantitativas de criação de valor para o acionista } \\
>\text { Compensação gerencial } \\
>\text { Perspectivas de novos projetos } \\
>\text { Projeções de lucro, vendas e crescimento }\end{array}$ \\
\hline
\end{tabular}

Fonte: Adaptado de Lanzana apud Pereira (2008, p. 35) 


\section{METODOLOGIA}

Objetivando analisar se as empresas listadas na BM\&FBovespa que fizeram doações a partidos políticos nas eleições municipais de 2008 e 2012 evidenciaram esse fato em seus demonstrativos financeiros, o estudo utilizou-se de uma metodologia que seguiu uma estratégia exploratória e descritiva, tendo em vista que o propósito desta pesquisa foi explorar uma realidade não conhecida.

A base inicial de dados foi composta pelos processos de prestação de contas anuais dos diretórios nacionais de cada partido político submetidos ao Tribunal Superior Eleitoral (TSE), disponíveis em <www.tse.jus.br>, referentes aos anos de 2008 e 2012, ou seja, apenas de eleições municipais, não levando em consideração os dados correspondentes às eleições de 2010. Em cada processo consta uma listagem constituída dos valores recebidos por doação e os respectivos doadores, estando esses valores apresentados em ordem cronológica por dia do ano. Para se definir as empresas a serem pesquisadas em relação às informações referentes ao ano de 2008, realizou-se uma separação entre pessoas físicas e jurídicas, por meio de uma reorganização dos dados de maneira a descobrir quanto cada uma delas doou aos partidos políticos. Obteve-se então uma planilha com mais de 300 linhas, contendo os nomes de cerca de 230 empresas.

Buscou-se então averiguar quais dessas empresas estavam listadas na BM\&FBovespa, além de informações a respeito do controle de cada uma, pois uma empresa não listada poderia ser controlada por outra que estivesse na lista. Foram excluídas da base de dados as empresas que não estavam elen- cadas na BM\&FBovespa, além daquelas que não eram controladas por alguma empresa que fosse listada.

Estabeleceu-se então um recorte pelo critério do valor total das doações, com intuito de obter as doações mais significativas. Foram excluídas da base de dados as empresas que realizaram doações menores que $R \$$ 1.000.000,00 (um milhão de reais). Dessa forma obteve-se a planilha final, composta de 11 empresas. Para análise dos valores correspondentes às doações correspondentes às eleições de 2012, foram consideradas apenas as 11 empresas pesquisadas em 2008, conforme o critério antes exposto, a saber: Andrade Gutierrez Participações S/A, Banco Bradesco S/A, Banco Santander (Brasil) S/A, Camargo Correia Cimentos S/A, Companhia Siderúrgica Nacional, Contax Participações S/A, Gerdau S/A, JBS S/A, JHSF Participações, Suzano Papel e Celulose S/A e Vale S/A.

Por meio do sistema de Divulgação Externa (DivExt) da BM\&FBovespa, foram obtidas as Informações Anuais (IAN) e os Demonstrativos Financeiros Padronizados (DFP) referentes aos anos de 2008 e 2012 das 11 empresas selecionadas, analisando-se os dados das IAN referentes ao controle sobre outras empresas e, quanto aos DFP, as Demonstrações do Resultado do Exercício, as Demonstrações do Fluxo de Caixa, as Notas Explicativas e os Relatórios da Administração em busca de alusões a doações efetuadas a partidos políticos.

\section{ANÁLISE DE RESULTADOS}

O valor total de doações recebidas pelos partidos políticos nas eleições do ano de 
2008 foi $R \$ 143.651 .817,00$, dos quais $R \$$ $52.935 .660,00(36,85 \%)$ foram doados pelas empresas listadas na BM\&FBovespa, que foram selecionadas para as análises deste estudo, enquanto $R \$ 90.716 .157,00$ $(63,15 \%)$ foram doados pelas demais empresas.

Já em relação ao ano de 2012, as doações de pessoas jurídicas aos partidos políticos brasileiros totalizaram $\mathrm{R} \$$ 451.356.543,94; valor bastante superior àqueles arrecadados quatro anos antes. Desse montante, as 11 empresas pesquisadas foram responsáveis pela transferência de $\mathrm{R} \$ 113.825 .000,00$, o que representa $25,21 \%$ do total. Esse valor corresponde a mais que o dobro das doações feitas por elas nas eleições municipais anteriores.

A seguir são apresentados os valores das doações efetuadas pelas 11 empresas aos partidos políticos. Os valores explicitados são o resultado da soma das doações efetuadas pelas empresas selecionadas e por suas controladas. Para melhor visualização dos dados, nesta tabela não foi considerado o destino das doações efetuadas, sendo expostos apenas os valores doados em sua totalidade.

Tabela 4. Empresas e respectivas doações aos partidos políticos

\begin{tabular}{|c|c|c|c|}
\hline Empresas & 2008 & 2012 & Total \\
\hline $\begin{array}{l}\text { Andrade Gutierrez } \\
\text { Participações S/A }\end{array}$ & $13.475 .000,00$ & $56.785 .000,00$ & $70.260 .000,00$ \\
\hline $\begin{array}{l}\text { Banco Bradesco } \\
\text { S/A }\end{array}$ & $9.050 .000,00$ & $2.575 .000,00$ & $11.625 .000,00$ \\
\hline $\begin{array}{l}\text { Banco Santander } \\
\text { (Brasil) S/A }\end{array}$ & $4.730 .000,00$ & $4.550 .000,00$ & $9.280 .000,00$ \\
\hline $\begin{array}{l}\text { Camargo Correa } \\
\text { Cimento S/A }\end{array}$ & $2.500 .000,00$ & $13.340 .000,00$ & $15.840 .000,00$ \\
\hline $\begin{array}{l}\text { Companhia Side- } \\
\text { rúrgica Nacional }\end{array}$ & $1.535 .660,00$ & - & $1.535 .660,00$ \\
\hline $\begin{array}{l}\text { Contax Participa- } \\
\text { ções S/A }\end{array}$ & $5.500 .000,00$ & $5.840 .000,00$ & $11.340 .000,00$ \\
\hline Gerdau S/A & $3.400 .000,00$ & $1.180 .000,00$ & $4.580 .000,00$ \\
\hline JBS S/A & $1.500 .000,00$ & $11.660 .000,00$ & $13.160 .000,00$ \\
\hline $\begin{array}{l}\text { JHSF Participa- } \\
\text { ções }\end{array}$ & $1.200 .000,00$ & $1.400 .000,00$ & $2.600 .000,00$ \\
\hline $\begin{array}{l}\text { Suzano Papel e } \\
\text { Celulose S/A }\end{array}$ & $2.515 .000,00$ & $675.000,00$ & $3.190 .000,00$ \\
\hline Vale S/A & $7.530 .000,00$ & $15.820 .000,00$ & $23.350 .000,00$ \\
\hline Total & $52.935 .660,00$ & $113.825 .000,00$ & $166.760 .660,00$ \\
\hline
\end{tabular}

Fonte: Elaboração própria com base nos dados do site do TSE 
Nas Eleições Municipais de 2008, das 11 empresas selecionadas para este trabalho de pesquisa, três fizeram doações a apenas um partido político: Camargo Correa Cimentos S/A, JBS S/A e JHSF Incorporações. As demais distribuíram suas doações a mais de um partido. Observou-se ainda que todas as oito empresas que diversificaram suas doações ofereceram quantias ao DEM e ao PT. Apenas a JBS S/A e a Camargo Correa Cimentos S/A não doaram valores ao DEM, assim como apenas a JHSF Incorporações S/A e a Camargo Correa Cimentos S/A não fizeram doações ao PT.

Dos oito partidos políticos contemplados com doações das empresas selecionadas, o PT foi o partido que recebeu mais doações, somando $R \$ 24.300 .000,00$. Por ou- tro lado, o PTB foi o partido que arrecadou menos doações, totalizando $\mathrm{R} \$ 750.000,00$. Percebeu-se certa centralização das quantias doadas, pois a soma dos recebimentos pelos cinco partidos com menores doações não alcança o montante adquirido pelo terceiro partido com maiores valores doados.

Em se tratando de valores doados em 2012, os partidos que menos receberam recursos foram o PEN e o PPL, com R\$50.000,00 e 100.000,00 respectivamente. O partido que mais recebeu doações de empresas listadas na Bolsa foi o PMDB, somando $\mathrm{R} \$$ 33.390.000,00.

Os dados percentuais da distribuição dos valores recebidos por partido político podem ser visualizados nos Gráfico 1 e Gráfico 2:

Gráfico 1. Distribuição percentual das doações entre os partidos políticos em 2008

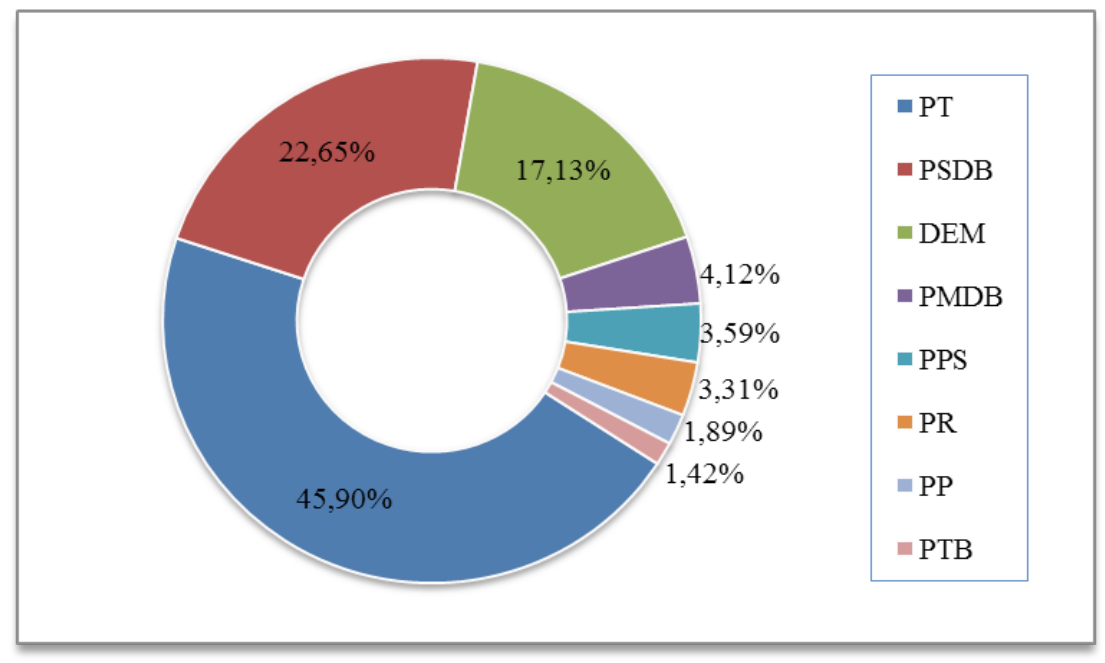

Fonte: Elaboração própria com base nos dados do site do TSE 
Gráfico 2. Distribuição percentual das doações entre os partidos políticos em 2012

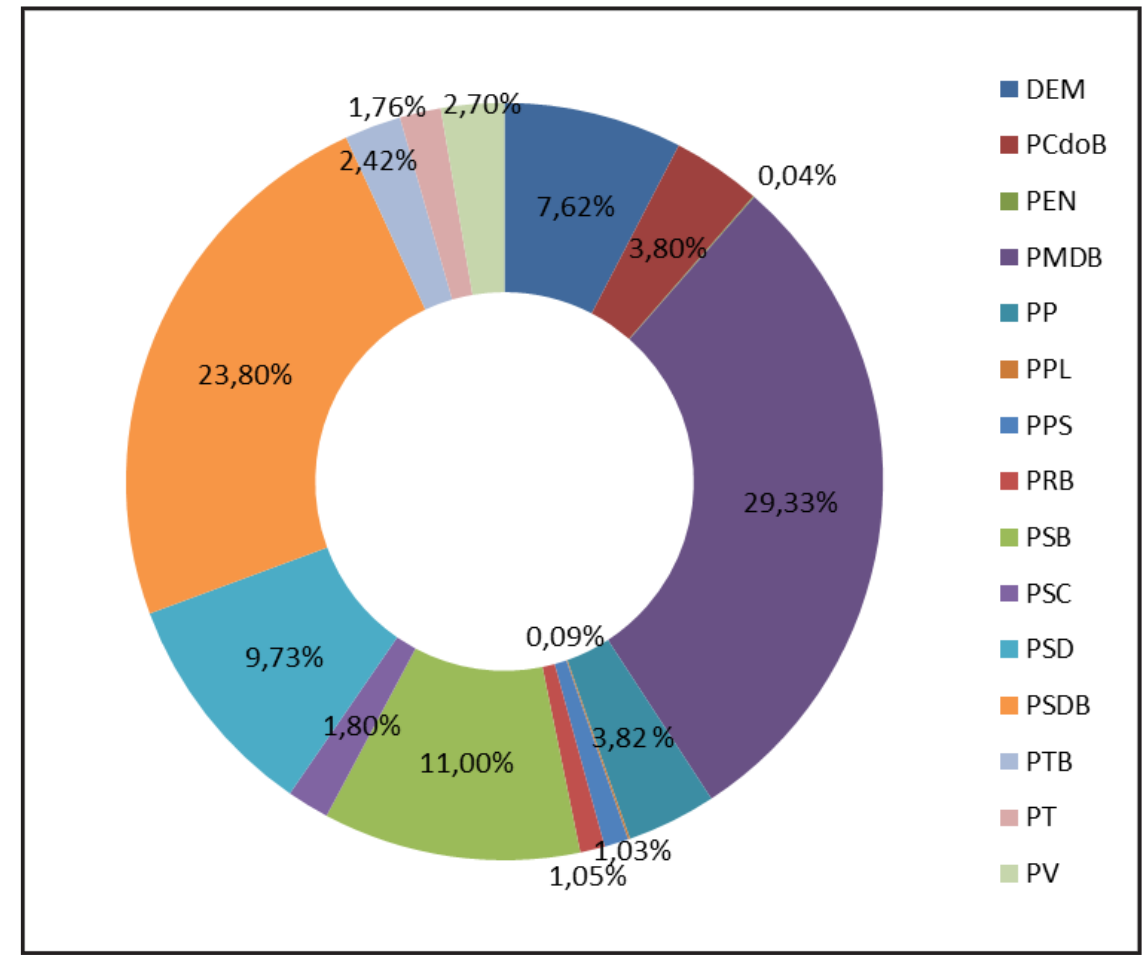

Fonte: Elaboração própria com base nos dados do site do TSE

A seguir, são apresentados os dados em detalhe sobre as doações, além do resultado das análises dos demonstrativos financeiros de cada empresa selecionada neste estudo.

Todas as doações da Andrade Gutierrez Participações S/A foram realizadas por meio de sua controlada Construtora Andrade Gutierrez S/A, que também foi responsável pela maior soma doada a um partido político no ano de 2008, destinada ao PT, no valor de $R \$ 5.850 .000,00$. Além disso, foi a empresa que teve a maior soma doada, em comparação com as demais, totalizando o valor de $\mathrm{R} \$ 13.475 .000,00$. Relativamente ao ano de 2012, a empresa continuou sendo a que proporcionou o maior volume de doações, atingindo $\mathrm{R} \$ 56.785 .000,00$. O Partido que mais recebeu recursos vindos da referida empresa foi o PMDB (R\$
15.875.000,00). A companhia não faz parte de nenhum segmento especial de listagem na BM\&FBovespa. Na análise das demonstrações contábeis inseridas nos DFP publicados pela empresa, além do relatório da administração, não foi encontrada nenhuma referência a doações realizadas a partidos políticos em nenhum dos anos.

O Banco Bradesco S/A fez doações, no ano de 2008, por meio das controladas Banco Alvorada S/A, responsável por $57 \%$ delas, e Alvorada Cartões Crédito e Financiamentos $\mathrm{S} / \mathrm{A}$, por $43 \%$, um total de $\mathrm{R} \$ 9.050 .000,00$. A companhia faz parte do Nível Diferenciado de Governança Corporativa - Nível 1 na BM\&FBovespa. Na análise das demonstrações contábeis inseridas nos DFP publicados pela empresa, além do relatório da administração, não foi encontrada nenhuma 
referência a doações realizadas a partidos políticos. No ano de 2012 o Banco foi responsável pela doação de $\mathrm{R} \$ 2.575 .000,00$ aos partidos políticos. As maiores doações foram realizadas ao DEM $(\mathrm{R} \$ 1.450 .000,00)$ e ao PMDB (R\$625.000,00).

O Banco Santander S/A doou um total de $\mathrm{R} \$ 4.730 .000,00$ em 2008 e $\mathrm{R} \$$ 4.550.000,00 em 2012. A companhia faz parte do Nível Diferenciado de Governança Corporativa - Nível 2 na BM\&FBovespa. $\mathrm{Na}$ análise das demonstrações contábeis inseridas nos DFP publicados pela empresa, além do relatório da administração, não foi encontrada nenhuma referência a doações realizadas a partidos políticos.

As doações da Cia Siderúrgica Nacional somaram $\mathrm{R} \$ 1.535 .660,00 \mathrm{em} 2008$, dos quais $R \$ 1.235 .660,00$ foram doados pela sua controlada Galvasud S/A. A companhia não faz parte de nenhum segmento especial de listagem na BM\&FBovespa. Na análise das demonstrações contábeis inseridas nos DFP publicados pela empresa, além do relatório da administração, não foi encontrada nenhuma referência a doações realizadas a partidos políticos.

A Contax Participações foi a empresa que fez doações à maior quantidade de partidos políticos nas eleições de 2008, num total de oito. Todas as doações foram feitas por meio de sua controlada TNL Contax S/A. Em 2012 as doações somaram R \$ $5.840 .000,00$, divididos para apenas por quatro partidos: DEM, PMDB, PSB e PSD. Quem mais recebeu recursos foi o PSD (R\$ 2.130.000,00). A companhia não faz parte de nenhum segmento especial de listagem na BM\&FBovespa. Na análise das demons- trações contábeis inseridas nos DFP publicados pela empresa, além do relatório da administração, não foi encontrada nenhuma referência a doações realizadas a partidos políticos.

Dos $\mathrm{R} \$ 3.440 .000,00$ doados pela Gerdau S/A em 2008, R\$ 2.440.000,00 foram por meio de suas controladas Gerdau Comercial de Aços S/A e Gerdau Aços Longos S/A. Entre as empresas pesquisadas e conforme os dados correspondentes às doações em 2012, a Gerdau é a que provavelmente tenha estabelecido algum critério para doações a partidos políticos, haja vista os valores serem equivalentes, $R \$ 100.000,00$ (PMDB e PT), R $\$ 150.000,00$ (PP), R $\$ 200.000,00$ (DEM e PCdoB), muito embora o PSDB tenha recebido $R \$ 430.000,00$. A companhia faz parte do Nível Diferenciado de Governança Corporativa - Nível 1 na BM\&FBovespa. $\mathrm{Na}$ análise das demonstrações contábeis inseridas nos DFP publicados pela empresa, além do relatório da administração, não foi encontrada nenhuma referência a doações realizadas a partidos políticos.

As doações da Vale S/A somaram $\mathrm{R} \$$ 7.530.000,00 em 2008. Todas as doações foram feitas por meio de suas controladas: Minerações Brasileiras Reunidas MBR S/A, Vale Manganês S/A e Rio Doce Manganês $S / A$. A companhia faz parte do Nível Diferenciado de Governança Corporativa - Nível 1 na BM\&FBovespa. Em 2012, as doações totalizaram $\mathrm{R} \$ 15.820 .000,00$. Na análise das demonstrações contábeis inseridas nos DFP publicados pela empresa, além do relatório da administração, não foi encontrada nenhuma referência a doações realizadas a partidos políticos. 
Jardson Edson Guedes da Silva Almeida, Luiz Antônio Félix Júnior, Umbelina Cravo Teixeira Lagioia, Juliana Araúijo, João Gabriel Nascimento Araújo

A JHSF Incorporações S/A doou R\$ $1.200 .000,00$ ao DEM, a JBS S/A, R\$ $1.500 .000,00$ ao PT e a Camargo Correa Cimentos S/A, R\$2.500.000,00 ao PSDB, em 2008. A Suzano Papel e Celulose S/A doou $R \$ 2.515 .000,00$ a dois partidos, com uma notável discrepância nos valores doados a cada um. As doações realizadas por essas empresas durante o ano de 2012 são: JHSF Incorporações S/A (R \$ 1.400.000,00), JBS S/A (R\$11.660.000,00), Camargo Correa Cimentos S/A (R\$13.340.000,00) e Suzano Papel e Celulose S/A (R\$ 675.000,00). A JHSF S/A e a JBS S/A fazem parte do segmento especial de listagem Novo Mercado, a Camargo Correa Cimentos S/A não integra nenhum segmento especial de listagem e a Suzano Papel e Celulose S/A se faz parte do Nível Diferenciado de Governança Corporativa - Nível 1 na BM\&FBovespa. Na análise das demonstrações contábeis inse- ridas nos DFP publicados pelas empresas JHSF S/A, JBS S/A e Camargo Correa Cimentos $S / A$, além dos respectivos relatórios da administração, não foi encontrada nenhuma referência a doações realizadas a partidos políticos.

A Suzano Papel e Celulose S/A foi a única empresa entre as selecionadas neste estudo que apresentou algum tipo de evidenciação referente à doação realizada a partidos políticos. No seu relatório da administração do ano de 2008 (e apenas neste ano), ela publicou o trecho reproduzido no quadro a seguir. Apesar de se destacar das demais entidades, a informação publicada pela Suzano é insuficiente, pois não discrimina a quais partidos as doações foram feitas e nem são expostos quais foram os critérios adotados para a determinação dos valores doados e dos destinatários.

\title{
Quadro 1. Trecho retirado do relatório da administração da Suzano Papel e Celulose S/A - 2008
}

\begin{abstract}
Temos contato com vários parlamentares, nos niveis estadual e federal, aos quais apresentamos com freqüência propostas e contribuicões à elaboracão ou ao encaminhamento de projetos relacionados ao setor. No âmbito do Judiciário, acompanhamos as decisões mais importantes para o mercado e Ações Diretas de Inconstitucionalidades. Já a atuação para a formulação de políticas públicas, com os governos, se dá no âmbito das entidades setoriais das quais participamos. Por meio delas, em 2008, debatemos e formulamos propostas relacionadas à Superintendência do Desenvolvimento do Nordeste (Sudene) e à Comissária de Despachos Amazônia - Codama.

[...]

Também fazemos contribuicões, financeiras, para políticos e partidos, sempre de forma transparente e respeitando as regras do Tribunal Superior Eleitoral (TSE), para o qual, em 2008, enviamos formulário explicitando nossa metodologia e os critérios adotados para definir as contribuicões.
\end{abstract}

Fonte: Divulgação Externa - BM\&FBovespa 
Os resultados encontrados neste estudo confirmam o que outros autores observaram ao analisar os níveis de evidenciação da informação no ambiente empresarial. Dantas, Zendersky e Niyama (2004) comentam que as empresas limitam-se a evidenciar o que é exigido pela legislação ou normas dos órgãos reguladores e relutam em aumentar 0 nível de evidenciação com o intuito de proteger informações de natureza estratégica. Dias Filho e Nakagawa (2001) mostram que mais importante do que fornecer um elevado número de informação é informar o que é necessário e de forma compreensível, possibilitando melhores resultados no processo decisório.

A falta de esclarecimentos a respeito das doações efetuadas para financiamento de campanhas eleitorais cria um ambiente de assimetria informacional no relacionamento entre a empresa e seus usuários externos, uma vez que os gastos não podem ser visualizados nos demonstrativos publicados pelas companhias. Essa assimetria se mostra presente pelo fato de que não é possível identificar as pessoas responsáveis pela decisão de realizar as doações aos partidos e os valores a serem doados, nem tampouco saber os parâmetros adotados para a entrega dos recursos. Pela leitura dos DFP, não é possível visualizar a relação que há entre as empresas selecionadas neste estudo e os partidos políticos, nem a motivação para elas contribuírem voluntariamente para o financiamento das campanhas eleitorais de determinado partido em detrimento de outro.
Como explicar, no ano de 2008, a decisão da Suzano Papel e Celulose S/A de doar R $\$$ $2.500 .000,00$ ao PT e $R \$ 15.000,00$ ao DEM? Ou a da Vale S/A de doar $R \$ 5.750 .000,00$ ao PT e R\$50.000,00 ao PTB? Ou a da Gerdau, que doou $R \$ 1.000 .000,00$ ao PSDB, ao PR e ao PT? Como explicar que a Contax Participações S/A fez doações a oito partidos diferentes e a JHSF Incorporações S/A a apenas um? Por que a JBS S/A só fez doações ao PT e a Camargo Correa Cimentos S/A somente ao PSDB? Os usuários externos das empresas selecionadas para este estudo que fizeram esses questionamentos ao ler os DFP ficarão sem resposta.

Durante o ano de 2012, a falta de critério nas doações, bem como a não apresentação de informações nos relatórios específicos das referidas empresas permanecem, assim como ocorrido em 2008. O Bradesco, por exemplo, fez doações que variaram de $R \$ 75.000,00$ (PSDB) a $R \$ 1.450 .000,00$ (DEM). O PT recebeu apenas 2.000.000,00; valor muito baixo se comparado aos $\mathrm{R} \$$ 24.300.000,00 no ano de 2008.

Uma possível explicação para a ausência de evidenciação dessas informações poderia recair sobre o princípio da materialidade na elaboração dos demonstrativos. Porém, é possível perceber que esse aspecto se rende à conveniência e oportunidade de divulgar determinado fato, a depender dos possíveis benefícios que a divulgação trará à empresa. Isso fica claro ao se observar um trecho do relatório da administração do Banco Bradesco S/A: 
Jardson Edson Guedes da Silva Almeida, Luiz Antônio Félix Júnior, Umbelina Cravo Teixeira Lagioia, Juliana Araúijo, João Gabriel Nascimento Araújo

Quadro 2. Trecho retirado do relatório da administração do Banco Bradesco S/A - 2008

\begin{abstract}
Cofundador da Fundação Amazonas Sustentável, entidade que contribuirá para o desenvolvimento sustentável e preservação da Floresta Amazônica, o Banco mantém também parceria com a Fundação SOS Mata Atlântica, com o objetivo de viabilizar projetos voltados à proteção desses ricos e ameaçados ecossistemas do planeta. Com recursos advindos de produtos como cartão de crédito, títulos de capitalização e financiamento de veículos, além de doações, já investiu, desde 1989, cerca de RȘ 74 milhões em programas de proteção de patrimônios naturais, históricos e culturais em áreas remanescentes da Mata Atlântica, em parceria com a Fundação SOS Mata Atlântica, viabilizando, dessa maneira, o plantio de mais de 26 milhões de árvores.
\end{abstract}

Fonte: Divulgação Externa - BM\&FBovespa

Distribuindo-se uniformemente os $R \$$ 74.000.000,00 investidos em áreas remanescentes da Mata Atlântica no período de 20 anos citado, tem-se uma média de $\mathrm{R} \$$ 3.700.000,00 investidos por ano, bem abaixo dos $\mathrm{R} \$ 9.050 .000,00$ doados durante o ano de 2008, aos quais não foi feita nenhuma referência no relatório.

Ao tratar da temática da produção e utilização de informações, Kam (1986) apud Lima et al. (2010) ensina que a informação é relevante para uma decisão se ela pode reduzir a incerteza sobre as variáveis inseridas no processo decisório. A falta de divulgação de informações que respondam a alguns dos questionamentos propostos anteriormente fragiliza a relevância e a confiabilidade das peças contábeis produzidas e publicadas aos usuários externos das empresas selecionadas, o que aumenta as incertezas sobre as variáveis envolvidas no processo de tomada de decisão.

A evidenciação não é uma convenção ou princípio contábil. Ela está relacionada ao objetivo da contabilidade de garantir informações de acordo com as necessidades dos usuários de forma que as demonstrações não se tornem enganosas (ludícibus,
2010).

A ciência contábil, por sua natureza social, está sujeita a inexatidões provocadas pelo aspecto comportamental e a níveis de subjetividade inerentes ao processo de construção dos demonstrativos. O que deve ser observado com cautela no momento da manipulação das informações é o limite entre a discricionariedade e a arbitrariedade de quem as detém. A influência de convicções políticas e a possível intenção de troca de interesses escusos camuflados sob o princípio da materialidade - ou outra justificativa qualquer na construção das demonstrações deturpam a essência e a finalidade da ciência, que é produzir informações relevantes e, acima de tudo, verdadeiras.

\section{CONCLUSÃO}

Em resposta ao objetivo proposto, conclui-se que apenas uma das 11 empresas selecionadas neste estudo evidenciou a realização de doações a partidos políticos na publicação dos Demonstrativos Financeiros Padronizados (DFP), somente no ano de 2008. Ainda assim, não foi possível identificar os valores doados nem os parâmetros e critérios adotados por ela para escolha dos par- 
tidos contemplados, gerando um ambiente de assimetria informacional para os usuários externos da entidade.

Os usuários externos à entidade têm nas informações contábeis um arcabouço teórico que os guiará no conhecimento da situação econômica, financeira e administrativa em que a empresa se encontra. A maior disponibilidade de informações diminui o grau de incerteza desses usuários a respeito dos resultados futuros da empresa, o que os auxiliará no processo de tomada de decisão. Para que seu objetivo seja alcançado, a contabilidade deve ser capaz de produzir informações relevantes sobre a entidade, visto que a comunicação delas se torna inócua se não houver utilidade para quem as recebe.

Nesse ambiente, a contabilidade deve atuar como o elo entre o meio corporativo e a sociedade, funcionando como agente de redução da assimetria informacional existente entre as vontades dos administradores e as necessidades dos usuários da informação (Lopes e Martins, 2005).

\section{REFERÊNCIAS}

Dantas, J. A., Zendersky, H. C., \& Niyama, J. K. (2004). A dualidade entre os benefícios do disclosure e a relutância das organizações em aumentar o grau de evidenciação. In: XXVIII EnANPAD, 2004, Curitiba. Recuperado em 10 nov., 2013, de www.anpad. org.br

Delaney, P. R., Adler, J. R., Epstein, B. J., \& Foran, M. F. (1996). Interpretation and application of generally accepted accounting principles. New York: John Wiley \& Sons.
Dias Filho, J. M., \& Nakagawa, M. (2001). Análise do processo da comunicação contábil: uma contribuição para a solução de problemas semânticos utilizando conceitos da teoria da comunicação. Revista Contabilidade \& Finanças. São Paulo, v. 15, n. 26, pp. 42-57, Mai./Ago. Recuperado de 14 out., 2013, de www.eac.fea.usp.br/eac/revista_ busca.asp

Hendriksen, E., \& Van Breda, M. (1999). Teoria da contabilidade. São Paulo: Atlas.

Instituto Brasileiro de Governança Corporativa (IBGC). (2013). Código das melhores práticas de Governança Corporativa. Recuperado de 8 nov., 2013, de www.ibgc.org.br/ Secao.aspx?CodSecao $=18$

ludícibus, S. (2010). Teoria da Contabilidade. 8a ed. São Paulo: Atlas.

ludícibus, S., Martins, E., \& Gelbcke, E. (2010). Manual de contabilidade das sociedades por ações (Aplicável às demais sociedades). 7a ed. São Paulo: Atlas.

Kam, V. (1986). Accounting Theory. 2nd ed. Wiley Inc.

Lagioia, U. C. T. (2007). Fundamentos de Mercado de Capitais. São Paulo: Atlas.

Lanzana, A. P. (2004). Relação entre disclosure e governança corporativa das empresas brasileiras. Dissertação (Mestrado) - Faculdade de Economia, Administração e Contabilidade da Universidade de São Paulo.

Lima, F. B., Lagioia, U. C. T., Nascimento, S. 
G.A. S., Lima, R. Q., \& Vasconcelos, A. L. F. S. (2010). Um estudo sobre a utilização da contabilidade gerencial pelas empresas pertencentes ao polo de confecção do agreste Pernambucano. Registro Contábil, v. 1, n. 1. Lopes, A., \& Martins, E. (2005). Teoria da contabilidade: uma nova abordagem. São Paulo: Atlas.

Pereira, D. M. V. G. (2008). Um estudo sobre a relação entre o lucro contábil e o disclosure das companhias abertas do setor de materiais básicos: evidências empíricas no mercado brasileiro de capitais. Dissertação (Mestrado em Ciências Contábeis) - Univer- sidade Federal de Pernambuco. Recife.

Schultz, C. A., Marques, T. O., \& Hofer, E. (2010). Análise do nível de disclosure voluntário de informações ambientais, econômicas e sociais em cooperativas do setor agropecuário. Congresso USP de Contabilidade e Controladoria.

Yuthas, K., Rogers, R., \& Dillard, J. F. (2002). Communicative Action and Corporate Annual Reports. Journal of Business Ethics, v. 41, pp. 141-157. 